\title{
Budget battle looms for US science agencies
}

\section{Competing spending priorities in the House of Representatives and Senate could push funding negotiations into December.}

\section{BY RACHAEL LALLENSACK}

S cientists in the United States are nervously watching from the sidelines as the annual budget skirmish heats up in Congress this week. Legislators are back in Washington DC from their August recess with an urgent list of tasks to complete before the fiscal year closes at the end of September. In addition to passing a budget to fund the government, lawmakers must raise the debt ceiling so that the country does not default on its loans, and discuss providing emergency-relief funding for victims of Hurricane Harvey.

But legislators are well behind on drafting their 2018 spending plans, which creates uncertainty about how much money science agencies including the National Institutes of Health (NIH) and NASA can expect.

Congress will probably pass a stopgap funding measure to keep the lights on, experts say. Agencies would remain on 2017 funding levels until lawmakers passed a new budget. In the meantime, they would be unable to start new programmes or end old ones without permission from Congress. "We're in for a wait," says Matthew Hourihan, director of the research and development budget and policy programme at the American Association for the Advancement of Science in Washington DC.

Hashing out the differences between spending bills from the House of Representatives and the Senate for the 2018 fiscal year could take until December, says Amy Scott, a sciencefunding and policy specialist at the Association of American Universities (AAU) in Washington DC.

\section{BRIDGING DIFFERENCES}

At the current stage of the budget process, the House and Senate diverge on several key scientific priorities. This is reflected in the appropriations bills that have already passed through the committees that oversee scientific agencies.

There is a large gulf in the plans for NASA. The House bill would boost the budget for the agency's science programme by US $\$ 94$ million over the 2017 level of $\$ 5.8$ billion, whereas the Senate would cut it by $\$ 193$ million.

The House has allocated $\$ 2.1$ billion for

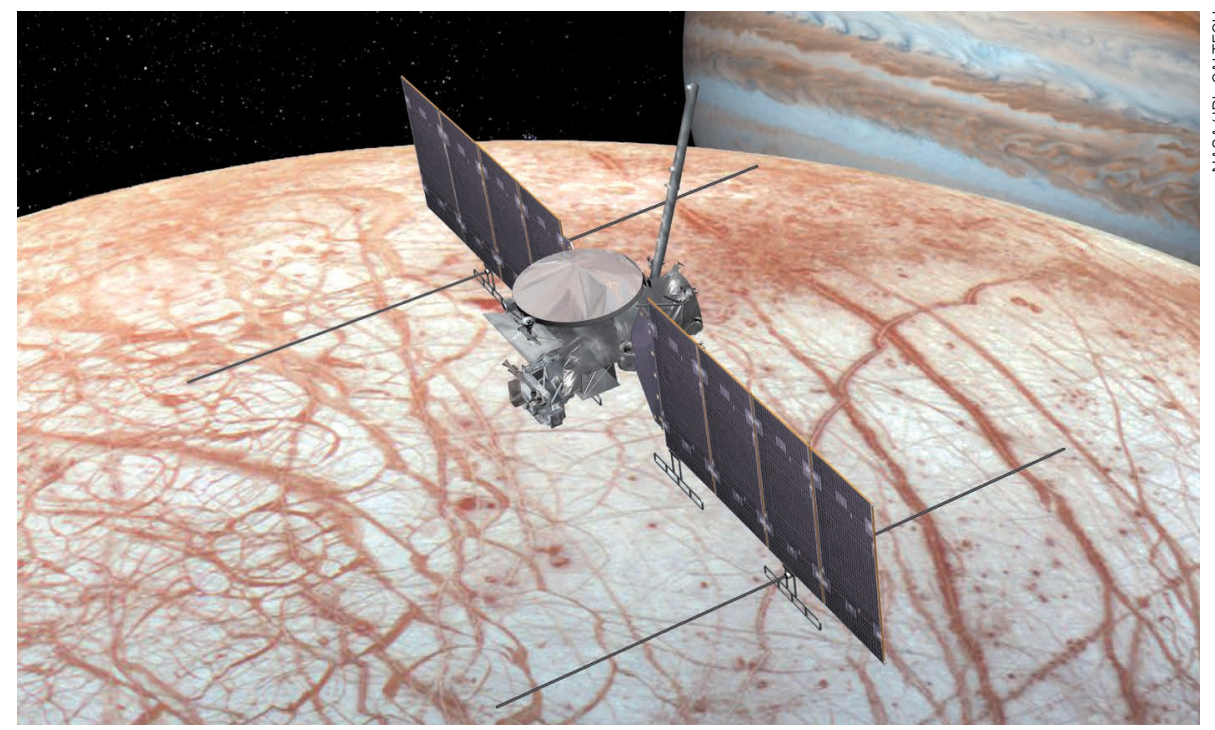

NASA's planned Europa missions are among government-funded research for which budgets are up in the air.

planetary science at NASA - up from the $\$ 1.8$ billion it received in 2017. But the Senate would cut $\$ 234$ million from current spending levels. Support from the House and Senate is reversed for Earth sciences. The Senate would maintain 2017 spending levels at $\$ 1.9$ billion, but the House would cut it by $\$ 217$ million for 2018. Despite this, negotiations to reconcile NASA's budget tend to go smoothly, says Scott.

A bigger sticking point is funding for the Advanced Research Projects Agency-Energy (ARPA-E), a Department of Energy (DOE) programme that incubates innovations in clean energy. The House bill guts ARPA-E, whereas the Senate gives it $\$ 330$ million for 2018 .

Criticism for the 8-year-old programme often stems from a perceived lack of output, says Julia Smith, a DOE funding and policy specialist at the AAU. "But ARPA-E is young, so we can't say how it has changed your life because we don't know yet."

Another bone of contention is support for the multibillion-euro nuclear-fusion collaboration ITER, which is funded by an international consortium that includes the DOE. The facility, under construction at a site in southern France, is over budget and suffering continual delays. Congress allocated $\$ 50$ million for the project in 2017, but the Senate has proposed eliminating its funding for 2018. The House would allocate $\$ 63$ million to ITER for 2018.

The National Oceanic and Atmospheric Administration (NOAA) may also face funding difficulties. The House slashes its 2018 budget to $\$ 5$ billion, down from the $\$ 5.7$ billion the agency received in 2017. The Senate has proposed $\$ 5.6$ billion for 2018 .

The divisions come to a head on NOAA's Polar Follow-On programme, which operates satellites that collect weather data. The House has proposed only $\$ 50$ million for this programme, down from its $\$ 329$-million budget in 2017. But the Senate would give it $\$ 419$ million.

It is unclear how items such as the funding aid package for Hurricane Harvey will affect budget and debt-limit negotiations, says Scott. Adding to the uncertainty is the fact that the Senate has yet to send half of its appropriations bills - including one that funds the NIH through the relevant spending committees.

Despite that, experts say that the NIH will probably get a boost from both the House and the Senate. Jennifer Zeitzer, director of legislative relations at the Federation of American Societies for Experimental Biology in Bethesda, Maryland, says that when it comes to the NIH, the two chambers "seem to be remarkably in agreement". 